\title{
Evolution and Development: some insights from Evolutionary Theory*
}

\author{
JEAN R. DAVID \\ CNRS, Laboratoire Populations, Génétique et Evolution, 91198-Gif-sur-Yvette, France \\ Manuscript received on June 27, 2001; accepted for publication on July 2, 2001; \\ presented by LENY A. CAVAlCANTE
}

\begin{abstract}
Developmental biology and evolutionary biology are both mature integrative disciplines which started in the $19^{\text {th }}$ century and then followed parallel and independent scientific pathways. Recently, a genetical component has stepped into both disciplines (developmental genetics and evolutionary genetics) pointing out the need for future convergent maturation. Indeed, the Evo-Devo approach is becoming popular among developmental biologists, based on the facts that distant groups share a common ancestry, that precise phylogenies can be worked out and that homologous genes often play similar roles during the development of very different organisms.

In this essay, I try to show that the real future of Evo-Devo thinking is still broader. The evolutionary theory is a set of diverse concepts which can and should be used in any biological field. Evolutionary thinking trains to ask « why » questions and to provide logical and plausible answers. It can shed some light on a diversity of general problems such as how to distinguish homologies from analogies, the costs and benefits of multicellularity, the origin of novel structures (e.g. the head), or the evolution of sexual reproduction. In the next decade, we may expect a progressive convergence between developmental genetics and quantitative genetics.
\end{abstract}

Key words: Quantitative genetics, multicellularity, analogy, homology, sexual reproduction.

\section{INTRODUCTION}

The relationship between development and evolution is becoming increasingly popular among developmental biologists. As stated by Th. Dobzhansky (1973), we know that "Nothing makes sense in Biology except in the light of Evolution' Developmental Biology and Evolutionary Biology are however mature disciplines which followed parallel but separate pathways during the last century. Time is now coming to bridge this gap (Maynard Smith and Sza-

\footnotetext{
* Invited paper

E-mail: david@pge.cnrs-gif.fr

Fax: 33.1.69.07.04.21
}

thmary 1995), and presumably much remains to be done. The purpose of this short review is to draw attention to some problems in development which can be enlightened if they are considered within the frame of extant evolutionary theory.

\section{THREE MAJOR QUESTIONS IN BIOLOGY: WHAT, HOW, WHY?}

The growth of biological endeavour has been strongly dependent of the kind of questions which were asked. The first basic and necessary approach is "what". The answers are mainly descriptive: what is the anatomy of a frog? What are the species 
existing in the Hawaiian archipelago? Taxonomy is basically a descriptive discipline, but even the mere inventory of extant species on earth is far from complete and requires further investigations.

A second step in biological knowledge is "how". How does this work? How does this develop? That is the major, central approach in modern experimental biology. It is applied to all levels of organisation from molecules to ecosystems, and tries to get answers to questions like: how a gene controls a protein synthesis; how two molecules interact; how the germ layers of an embryo arise from a single cell; how so many Drosophila species coexist in the Hawaiian archipelago.

Experimental, functional analysis is at the core of modern biology, it implies an analytical approach and leads to the major discoveries. Any system investigated is subdivided into parts, which are easier to handle and to analyse. In this respect there is both a temptation and a danger of reductionism. Reductionism will try to explain the functioning of a complex biological system by the mere addition of its known parts, while an increase in complexity always leads to the appearance of new, emerging, unexpected properties. The sequencing of entire genomes is certainly a major progress in biological knowledge, but it will not explain directly the realisation of an organism. Indeed, sequencing is more a "what" question than a "how" one. Since biological processes are integrated at different levels of complexity (molecules, cells, organisms, populations and ecosystems) and since, at each level, new emergent properties appear, it is both necessary and justified to tackle simultaneously all these levels. There should not be any hierarchy among biological disciplines, but only discrimination between good innovative science and poor repetitive science.

The third kind of question is "why". Why are there bacteria and elephants? Why micro-organisms and Metazoa? Why so many (over 1000) Drosophila species in Hawaii? Why species at all? Why is sometimes considered a crazy question, but it is also a pervading interrogation since the beginning of historical times. Why are there living beings on earth?
Why are there humans? In the absence of scientific knowledge, philosophers tried to answer these questions and the recurrent explanation in almost all civilisations was creation: there was nothing to understand further. Only the accumulation of what and how answers during the last three centuries has permitted the birth and the growth of another explanation: all living organisms share a common ancestry and have evolved and diversified during almost four billion years of earth history. Biological evolution, not creation, is the general and now well recognised process. Much however still remains to be explained and this is the goal of a mature discipline in life sciences: evolutionary biology. It is a difficult discipline for at least two main reasons. First, as stated above, it must integrate, interpret and explain all kinds of biological information at all levels of integration. Second, being basically an historical approach, it is in many cases not amenable to an experimental analysis. In other words, many hypotheses and interpretations in evolutionary biology cannot be falsified in the sense of Popper (1972). Evolutionists, using a comparative method, are proposing plausible interpretations, often implementing mathematical techniques. These models may be falsified or improved by further observations.

Being based on a principle of inheritance with change over generations in natural populations, evolutionary biology needed to integrate all the information from genetics, especially from population genetics. Finding now the same genes in different species and distant taxa has been a further "verification" of the evolutionary theory and has permitted to work out molecular phylogenies, providing an irreplaceable historical information. More recently major conceptual progresses have been made at a higher integrated level, in interpreting the evolution of life histories (Charlesworth 1980, Charnov 1993, Roff 1992, Stearns 1992). This rapidly expanding field, at the crossroads between observations and theories, tries to explain why bacteria and elephants coexist in nature.

During the maturation years of evolutionary theory, embryological information has played a 
fairly marginal role, in spite of the fact that most extant species are multicellular. Having realised that identical genes are expressed in very different groups and lineages, developmental biologists are now aware that they must integrate evolutionary information in their research, at least the historical and phylogenetic aspects. Evolutionary biologists, on the other hand, will discover the diversity and richness of problems raised by the development of highly complex multicellular organisms. Time is coming for a convergent evolution of the two disciplines.

\section{HISTORICAL OVERVIEW: THE EVOLUTIONARY THEORY AT THE BEGINNING}

With the exception of a few creationists, biological evolution is now recognised as a well established occurrence. Such was not always the case. Some ideas about evolution may be found among ancient philosophers as well as in the works of Buffon (1749-1804, see Mayr 1982) but the first clear formalisation dates back to Lamarck (1809). Following Linné, the classification of plants and animals used morphological similarity in order to establish hierarchical taxa at various levels (e.g., genera, families, orders). The general interpretation was similarity by kind, that is, those animals looking alike, such as horses and donkeys, had been created to perform similar functions in nature. The basic idea of Lamarck was that similarity was more easily explained by a common ancestral origin. Of course, such an hypothesis, called transformism, needed a mechanism. At that time, nothing was known about heredity. It was however quite obvious that different environments and ways of life might result in large variations of phenotypes (what we call now phenotypic plasticity). Lamarck proposed that such changes, induced in parents, would be passed on to offspring, a mechanism called inheritance of acquired characters.

Some time later, Geoffroy St. Hilaire (see Piveteau 1950 and Le Guyader 1998), comparing different animal phyla, tried to establish a single plan of organisation. His comparison of the anatomy of a vertebrate and of an arthropod (a lobster) remains a well remembered example. His idea was to find homologous organs in distant phyla, an argument for a single plan of organisation, and of course for a possible evolution from a single ancestor. This "théorie des analogues', (homologous organs were called analogous) was fiercely fighted by Cuvier, a bright comparative anatomist, but a fixist and a creationist.

The idea of Evolution was extended three decades later by Darwin (1859). Again, nothing was precisely known about heredity, and Darwin believed in the heredity of acquired characters. His theory of gemmules, elaborated later, also turned out to be wrong. The merit of Darwin, however, was to suggest and argue for a mechanism of evolution, which is natural selection. Still now natural selection, with its multiple aspects, appears as the central mechanism of biological evolution.

\section{THE EVOLUTIONARY TREE OF LIFE}

In modern science, a broad diversity of information helps to feature how life was born on earth, and how and when the different groups now observed in nature originated. Such inferences and reconstruction are mainly based on two very different kinds of data: the fossil record and molecular phylogenies.

Broadly speaking, the surface of our planet solidified about four billion years ago. In a relatively short period (500 million years) prebiotic systems evolved and produced cells surrounded by a membrane, more or less similar to extant bacteria. Typical bacterial constructions, the stromatolithes, are now observed along the seashore, but already existed three billion years ago. The further evolution of Prokaryotes (Bacteria and Archea) was fairly slow with little phenotypic changes. A major event, which took place about two billion years ago, was the emergence of Eukaryotes, that is, of cells with a nucleus and many other cellular characteristics. The origin of Eukaryotes is still debated. Molecular investigations have shown that, according to the kind of genes which are compared, Eukaryotes appear to 
be closer either to Bacteria or to Archea. Of course the fossil documents are very scarce. A novel theory now spreading among biologists, assumes that the first ancestral Eukaryote arose from a symbiosis between a Bacterium and an Archea: the membrane of the internal symbiont produced the nuclear membrane, and the two genomes progressively fused into a single one, within the nucleus. The acquisition of a bigger and more complex genome was followed by further major changes. We may recall the origin of mitochondria from another cytoplasmic bacterial symbiont and the acquisition of photosynthesis (chloroplasts) from symbiotic cyanobacteria.

For a long evolutionary time, Eukarya remained unicellular but produced a broad diversity of phyla still found in the extant world. These unicellular eukaryotes are often classified in a single cluster, or kingdom, called Protista, although they include a diversity of clades and are obviously paraphyletic. During their evolution, Eukaryotes acquired progressively new properties and organelles, such as chromosomes, mitosis and presumably meiosis. Possible mechanisms can be suggested from a comparison of what now exists in the living world (Maynard Smith and Szathmary 1995) while the fossil record is useless.

\section{MULTICELLULARITY - A MAJOR RECURRENT EVOLUTIONARY CHANGE}

Most species in the extant world are multicellular organisms (plants and animals) living on continents. About a billion years ago, all organisms were unicellular and lived in oceans. The progressive colonisation of terrestrial biota is quite well documented thanks to fossils, comparative anatomy and phylogenetic reconstruction. This was accompanied by spectacular new phenomena such as increase in body size, diversification of life histories and ecological niches, and more complex interactions between species.

Multicellularity is a recurrent phenomenon which occurred independently several times (Baldauf et al. 2000). Multicellular animals (i.e. Metazoa) appear as a monophyletic clade. Terrestrial plants are another one, and also Fungi. Multicellularity is also observed in algae, among Protista (e.g. slime molds) or among Bacteria (stromatolithes).

Multicellularity raises a major challenge for evolutionary theory. In terms of Darwinian fitness, multicellularity implies, in a primitive stage, that some cells will not contribute to the next generation: they remain somatic for the benefit of their sisters. In other words, they become altruistic and the evolution of altruism, as observed in animal societies, was already a challenge for Darwin. Another problem is that multicellularity is accompanied by a delay in reproduction, and a decrease in the number of offspring, both resulting in an apparent decrease in the fitness of the population. In the next section, I shall try to explain how modern theory solves these apparent evolutionary paradoxes.

\section{EXPLAINING THE ORIGIN OF MULTICELLULARITY}

The paradox of altruistic behaviour in animal societies was explained by the concepts of kin selection and inclusive fitness (Hamilton 1964). An altruistic gene may invade a population if the sacrifice of one female (males are not considered in demographic analyses) permits the survival of more than two sisters (two sisters will harbour on average one altruistic allele, since the genetic similarity among sisters is $50 \%$ ). In the case of a multicellular organism, altruism will be easier since all cells share the same genotype. However, the reduction in fitness of a multicellular variant will be more pronounced since, in most cases, many cells fail (renounce) to reproduce.

For example, among Volvocales (phytoflagellates) different related species exist, some remaining unicellular while others build multicellular entities. Under favourable laboratory conditions, a unicellular form will rapidly eliminate a multicellular one, thanks to a higher proliferative capacity accompanied by a low mortality. The picture changes completely if some predator is introduced. Big individuals will be protected by their size while unicellular ones will be eaten and will decrease in num- 
ber. This simple example illustrates how different species may coexist. It is not possible for a single species to acquire all possible advantages without paying for some inconveniences; otherwise only one species would ultimately survive on earth.

A rapid rate of reproduction favouring the invasive capacity is accompanied by a vulnerability to predation. A big size, on the other hand, may protect from predation and may offer some other advantages, but will imply a longer generation time and a lesser rate of proliferation. More generally any adaptive change in one direction which provides some benefit in terms of fitness, is likely to be accompanied by a cost from another point of view. Evolutionary biologists describe such negative correlations as trade-offs. During the last two decades, major conceptual progresses have been made using the concept of trade-off, for interpreting the diversity of life histories (Charnov 1993, Roff 1992, Stearns 1992). In the extant world, trade-off is the ultimate cause of species coexistence, and it explains why it is possible to be a weed or a tree, a mouse or an elephant. Bacteria have remained very small and quite simple since they appeared more than three billion years ago, but they are still doing very well. Metazoa are much more complex and much bigger. But as stated by all evolutionists, complexity is not an indication of a general tendency toward some progress (Gould 1996). The human species, which may be considered as a summum of complexity is, in other respects, very vulnerable. Multicellularity has certainly been a means for producing a bigger size, thus avoiding predation or becoming a predator. But other interpretations have been considered, for example, a better metabolic utilisation of the environmental conditions (Bonner 2000).

Another problem with multicellularity is that it implies some change at the genetic level. A modification in the genetic program is likely when two cells which arise from a mitosis, remain together and eventually change their phenotypes and their functions. Such changes however do not modify the genome in a permanent way, like mutations. More likely they involve changes in the way genes are regulated by epigenetic processes (Ohlsson et al. 1995, Jablonka and Lamb 1995, Russo et al. 1996 , Steele et al. 1998). Cell differentiation, which is a major but still poorly understood issue in developmental biology, is almost exclusively an epigenetic, more or less reversible phenomenon. Theoretical evolutionists now try to understand how such epigenetic changes (sometimes called epimutations) may spread in a population. Much remains to be done in this way of thinking.

\section{ANALOGIES AND HOMOLOGIES}

An ancient but still valid and modern debate in evolutionary biology, and also for understanding development, is to distinguish analogies from homologies.

Convergent, recurrent adaptations are likely to occur when a strong selective pressure exists: this will produce analogous organs or functions. For example the wing of a fly and the wing of a bird share a common function, bear the same name but have completely independent origins. The problem becomes however more complex if we compare bats and birds, two kinds flying vertebrates. In both cases, the forelimb has been transformed into a wing. In this respect, wings are homologous to the anterior legs of Amphibia and Reptilia, and can be thus considered, at the forelimb level, as homologous. But the flight function results from convergent, independent adaptations that are the transformation of an anterior leg into a wing: in this respect, the wings of birds and bats are analogous organs. The above example is easy to understand, but in other cases, the origin of an organ by evolutionary transformation may be very difficult to solve. For example, the wings of insects are considered as derivatives either of segmental gills or of lateral expansions of thoracic tergites (Brodsky 1994). It is however generally assumed that all insect wings share a common origin, i.e. are homologous.

The development of molecular biology and the search for molecular phylogenies has brought a new interest concerning the problem of homologous or analogous genes and functions. By comparing the 
sequences (DNA or amino-acids) of two genes, it is generally easy to decide whether they are homologous, deriving from a common ancestor or not. An identity of function, for example the same EC code for an enzyme, does not however implies homology. For example, all alcohol dehydrogenases $(\mathrm{ADH})$ share the same code: EC 1.1.1.1. However, at the molecular level, the ADHs of yeast, maize and mammals are homologous while the Drosophila $\mathrm{ADH}$ is a much smaller, analogous molecule.

Evolutionists are also aware that, in the course of Evolution, gene duplications have been common (Ohno 1970) providing an opportunity for acquiring new functions. This has led to a classical problem in phylogenetic analyses. When comparing genes in different species, there are two kinds of homologies: orthologous genes derive directly from a single ancestor and have diverged after the last specific split; paralogous genes have different ancestries in closely related species, since they originated from a much older gene duplication. It is misleading to use and compare paralogous genes while believing they are orthologous. As we shall see it in the next sections, analogies and homologies are a permanent, difficult and recurrent problem in all studies of evolution and development.

\section{THE ORIGIN AND EVOLUTION OF DEVELOPMENTAL NOVELTIES}

Evolutionary biologists are aware that adaptations are constrained by historical features, especially by phylogenies, so that evolutionary changes are more akin to an erratic tinkering than a general directional trend (Jacob 1977, Gould 1996). From a functional point of view, we easily understand a loss of function, for example the origin of snakes from lizardlike ancestors. We also understand the transformation of an anterior leg into a wing, especially because we recognise the same bones in both organs. It is far more difficult to imagine how a tetrapod vertebrate might evolve into a hexapod. Most scientists will consider such a change as impossible. In other words, once the tetrapod state was acquired in terrestrial vertebrates, it became a strong developmen- tal constraint which did not permit eventual major changes.

The observation of such constraints has led many authors to say that Darwinian theory explained microevolution (that is small adaptive variations) but not macroevolution, defined as the appearance of major novelties, such as limbs or head. This opposition still remains a debate among evolutionists, but it is progressively solved by a better understanding of both phylogenies and comparative developmental genetics.

In the Chordate phylum, it is likely that an ancestral state was like the extant Amphioxus, deprived of limbs. Then limbs appeared presumably as lateral expansions along the body. Why only two pairs and not three have been retained in the derived groups is not understood.

We have more information concerning the origin of the head in Vertebrates. Again, the Amphioxus-like ancestor was presumably deprived of a differentiated head, without eyes or mouth and with only a slight anterior dilatation of the neural tube. In the course of evolution, a major developmental novelty appeared, that is, a special derivative of the nervous tube, the neural crest. Modern developmental investigations have shown that the neural crest plays a major role in the organisation of the nervous system in Vertebrates and especially in the building of the head (Le Douarin and Kalcheim 1999), including the brain and the skull. Without the neural crest, the evolution of Vertebrates toward a bigger size and the acquisition of a complex brain would have been impossible. How the neural crest itself originated during chordates evolution is not known. Future progresses of developmental genetics should shed some light upon this major problem.

\section{THE ANTERO-POSTERIOR AXIS: A MAJOR SUCCESS OF DEVELOPMENTAL GENETICS}

Evolution and development (Evo-Devo) is becoming a fashionable preoccupation in modern biology. This is due to the fact that evolutionists discover development, while developmental biologists discover evolution. I believe that a major reason 
for this common interest originated in the unexpected discovery that the early stages of embryonic development and especially the establishment of the antero-posterior axis were homologous features in Drosophila and Vertebrates. More precisely, Drosophila geneticists progressively identified a series of genes (called homeotic) which were responsible for the fate of successive body segments and for their differentiation into head, thorax and abdomen. Surprisingly, there was a colinearity between the order of these homeotic genes on the third chromosome, and of their expression along the anteroposterior axis of the embryo. When these genes were cloned, it was rapidly found that they also existed in Vertebrates, and surprisingly in the same order on the chromosome (Gehring 1998). More precisely these genes, called Hox genes, form four paralogous clusters on four different chromosomes. The existence of these four clusters confirms the hypothesis put forward three decades ago (Ohno 1970) that, during Vertebrate evolution, two successive tetraploidisations took place.

The similar order of the genes in Vertebrates and Drosophila (and in several other phyla) implies for example that the same genes are expressed in the head of both taxa. It was tempting at the beginning to assume that the head of a fruit fly and the head of a mouse might be homologous organs. However this conclusion would be wrong. Drosophila and Vertebrates are distantly related Metazoa. Vertebrates belong to chordates within Deuterostomia while Drosophila belongs to Ecdysozoa within Protostomia (De Rosa et al. 1999). We have seen that in chordates, an ancestral state was very likely deprived of a differentiated head, and that the Vertebrate head was a new acquisition depending on the neural crest. Besides Arthropods, Ecdysozoa comprise other phyla which, like nematodes, do not possess a differentiated head (De Rosa et al. 1999). The absence of a head is likely a primitive state; in other words, the insect head is also likely to be a new acquisition, rather than being homologous to the vertebrate head.

The fact that the same genes are expressed dur- ing head development in both Drosophila and Vertebrates must be considered as an analogy and an evolutionary convergence. Why this convergence used the same genes to produce analogous organs is unclear. One interpretation is that evolution was constrained by a limited set of developmental genes and was obliged to reutilize the same genes for building new organs and new functions. It is also possible that the functional order of the homeotic genes along the chromosome was an additional constraint, preventing the building of a head with completely unrelated genes.

\section{ANOTHER DEVELOPMENTAL AND EVOLUTIONARY PARADIGM: THE ORIGIN OF THE EYES}

Eyes are obviously made to see, and they are found in most animal phyla. In some cases, they are very complex organs, performing their function close to perfection. In the early time of Darwinism, eyes were often taken as an argument to say that such complex structures could not proceed from a gradualistic evolutionary process. In other words, and in the same way that finding a watch implied a watchmaker, the observation of the perfect eye of a bird implied some intention in evolution, and has long been a creationist argument. Improvements in scientific knowledge have progressively changed the way we see and understand the evolution and development of the eye.

It was recently shown (Nilsson and Pelger 1994) by computer simulation, that a simple flat photoreceptor could evolve progressively into a complex spherical eye with a lens, by fixation of random mutations through natural selection.

The diversity of eyes which are found for example among molluscs (Strickberger 1990) is best explained by a gradualistic evolution and different levels of selective pressure. The similarity of complex eyes as found in an octopus and a vertebrate is simply due to convergent adaptive evolution. If eyes are recurrent adaptations occurring in diverse phyla, the question is: 'Does Developmental Biology provide some interesting insight about eye evolution?'

A positive answer was provided when it was 
shown in Drosophila that an over expression of a gene (the protein of eyeless) could induce the formation of ectopic eyes (Gehring 1998). The eyeless gene is homologous to Pax 6 in vertebrates, and mutants of the two genes result in eye abnormalities in fruit flies and vertebrates respectively. A possible but wrong conclusion would be that, despite their anatomical differences, eyes in insects and vertebrate are homologous. What is homologous in the two phyla is the basic process of inducing some cells into the photoreception pathways, with the production of the photosensitive protein, opsin. During the development of the eyes, the two genes are used again for morphological differentiation, including lens production in vertebrates, but these later functions are pure analogies.

How various genes, having a diversity of basic functions, may be recruited to perform a new task, is best illustrated by the lens proteins (crystalline) in vertebrates (Gerhart and Kirschner 1997).

The new function just consists in making a transparent solution within the lens, and many proteins can do that. Lens proteins are very diverse: some are constitutive, i.e., general proteins expressed in all species. But others are metabolic enzymes which have found a new site of expression, but no metabolic function: for example, lactate dehydrogenase in birds, alcohol dehydrogenase in camels, aldehyde dehydrogenase in macroscelids.

\section{SEXUAL REPRODUCTION: A POORLY UNDERSTOOD AND RECURRENT EVOLUTIONARY DILEMMA}

Already for Darwin (1871), sexual reproduction and sexual selection appeared as a specific, but difficult problem. Since these times much attention has been paid by both evolutionists and developmental biologists to the understanding of sexuality, but a deep gap still persists between the two approaches.

In most animal species sexes are separated, about $50 \%$ of individuals are males, $50 \%$ are females. From an ecological and evolutionary point of view, this proportion is not an optimum. Optimising selection should favour species in which there are more females than males. Why this is not so is generally explained by genetical constraints. In most species, sex appears to be transmitted as a simple Mendelian character, leading to a 50-50 segregation. Only in a few groups, such as reptiles or haplodiploid arthropods, sex is not genetically determined, and the sex ratio may vary, often in an adaptive way, i.e. producing more females than males.

Indeed, the occurrence of sexual reproduction is, within evolutionary theory, a puzzle and a dilemma. It is commonly argued that sexual reproduction which implies not only fertilisation, zygote production and embryonic development, but also genetic exchanges among different individuals of the same species, is a means for conserving the genetic diversity, keeping the genetic load at an acceptable level and permitting eventually new adaptations and evolutions.

But all these are supposed long-term advantages, in opposition with short-term disadvantages (Maynard Smith 1978). Although most animals are gonochoric (two sexes) many are parthenogenetic, that is reproduction occurs without fertilisation and by a direct development from female gametes. Parthenogenesis is a recurrent phenomenon which has evolved independently from bisexual species in many groups. From a theoretical point of view, it is easy to show that a parthenogenetic mutant, appearing in a bisexual species, should invade the population and outcompete the gonochoric form. In other words, parthenogenesis should be the general way of reproduction, and why it is not so remains a dilemma. Evolutionists are obliged to suggest ad hoc arguments, and the most general one is that parthenogenetic organisms are made of clones with a low genetic diversity. This should prevent their adaptation to changing environments and result in high rates of extinction. In other words, the shortterm advantage of parthenogenesis should be counterbalanced by a long-term disadvantage. It is also possible, for example in Mammals, that parthenogenesis is not possible due to genetic imprinting and the differential expression of genes coming from the sperm or the oocyte in the embryo.

Developmental biologists have also long been 
fascinated by sexuality. In Vertebrates, we know than sex hormones play a major role in the differentiation of primary and secondary sexual characters. In Drosophila, on the other hand, each cell is autonomous and capable of expressing independently its own sexual genotype and no hormones are involved.

Sex differentiation has been analysed not only by classical experiments of developmental biology such as grafts and extirpations, but also by genetic means. Indeed, it has been the first great success of developmental genetics. To summarise the results shortly, sex is determined in Drosophila by a succession of genetic cascades acting within each cell. In Mammals, the primary induction of the male hormone in the testis will eventually determine the whole male phenotype. In the female, the absence of male hormone permits the differentiation of the female phenotype.

Sexes are phenotypes which are very strongly constrained, or canalised, by natural selection. Individuals must be normal males or normal females for mating and reproduction. Genetic dissections of sexual phenotypes have produced intermediate individuals which are almost always abnormal and sterile. So the question is: 'How is the genetic determinism of sex able to evolve?'

The strong constraints existing on phenotypes suggest that, as for the antero-posterior axis of early embryos, we should find genetic homologies in sex determination of distantly related taxa. Developmental genetics did show exactly the reverse. The genetics of sex determination is a fast evolving trait; sexual phenotypes are pure analogies. Different evolutionary pathways are visible not only between distant taxa (e.g. arthropods and vertebrates) but also within arthropods (Bull 1983): for example, a sex hormone, the androgenic hormone is responsible of male differentiation in Crustacea. Even within the same insect order, major differences are found: genetic determinisms of sex in houseflies or mosquitoes are very different from that of Drosophila.

Here is a clash between developmental and evolutionary biology. Developmental genetics has revealed a high diversity among mechanisms of sex determination, presenting sex as a relatively fast evolving trait producing analogous phenotypes. Evolutionary biologists, however, cannot understand and explain how it is possible to evolve from one genetic system to another one, since any genetic change is likely to produce abnormal, sterile individuals. The only possibility I can see for the moment is that such a transition might occur by the intermediary of a relatively neutral form, that is, a parthenogenetic lineage. In such a lineage, stabilising selection on sexual phenotypes would be released, permitting some genetic changes. In the long-term, but for unknown reasons, a new male phenotype could appear with an original genetic basis. Of course, this hypothesis requires further theoretical analyses, in order to understand why and how a neo-male might occur.

\section{CONCLUDING REMARKS}

As stated previously, evolutionary biology is required to integrate all kinds of biological information into a coherent theory of biological evolution, and of course all what is learnt from developmental biology and developmental genetics. In this essay I tried to show, with a few examples, how an evolutionary thinking, and especially asking "why" questions, could highlight some aspects of developmental biology. Evolutionary biology is not restricted to the task of explaining relatedness and phylogenies among species or clades. It asks general questions such as why are there multicellular organisms, why are there sexes, are similar traits homologous or convergent, etc. The answers attempt to be plausible, coherent and with a maximum likelihood. They are permanently subjected to modelisations, simulations, general confrontations and become progressively more satisfying for the scientific community.

Both disciplines now integrate genetic analysis - developmental genetics and evolutionary genetics. Up to now, there has been little overlap between 
these two fields, for one main reason. Developmental genetics has focused mainly on the early stages of embryonic development, unravelling the general orientation of the future organism, the origin of the segments, of the nervous system etc. Evolutionary genetics, at least in its functional aspects, has focused on complex, adult phenotypes. Adaptive genetic variations are generally described with statistical means, the responsible genes being considered as a blackbox. Only recently the search of QTL (quantitative trait loci) has become a major task for quantitative geneticists.

After unravelling the early stages of embryonic development, developmental genetics is now more concerned by later stages and the determinism of adult phenotype. Not surprisingly numerous " early development genes" are highly pleiotropic and expressed in various organs until the adult stage. QTL detected by phenotypic studies often turn out to be identical to previously known developmental genes. The major challenge of developmental genetics will be to understand the regulatory mechanisms of gene expression which are responsible of cell differentiation. But on the phenotypic side, we already know that QTL often imply a polymorphism not at the protein level, but in the regulatory sequences of a gene. In this respect we see a strong convergence between the two approaches. Time is coming when developmental genetics and quantitative genetics will fuse into a single discipline, tentatively called now functional genomics.

\section{ACKNOWLEDGEMENTS}

I thank Drs. F. Dieterlen and N.M. Le Douarin for helpful comments on this essay, and $\mathrm{H}$. Legout for help in the preparation of the manuscript.

\section{RESUMO}

A biologia do desenvolvimento e a biologia evolutiva são ambas disciplinas integrativas maduras que se iniciaram no século XIX e seguiram vias científicas paralelas. Recentemente, um componente genético foi introduzido em ambas as disciplinas (genética do desenvolvimento e genética evolutiva) indicando a necessidade de maturação convergente no futuro. Em verdade, a abordagem "Evo-Devo" está se tornando popular entre os estudiosos da biologia do desenvolvimento, baseada nos fatos de que grupos distantes compartilham uma ancestralidade comum, que filogenias precisas podem ser obtidas e que genes homólogos frequentemente desempenham papéis similares durante o desenvolvimento de organismos muito diferentes.

Neste ensaio, eu tento mostrar que o futuro real do pensamento "Evo-Devo" é ainda mais amplo. A teoria evolutiva é um conjunto de diversos conceitos que podem e deveriam ser usados em qualquer campo biológico. $\mathrm{O}$ pensamento evolutivo instrui a indagar questões do tipo "por que" e a fornecer respostas lógicas plausíveis. Este pensamento pode lançar alguma luz sobre uma gama de problemas gerais tais como distinguir homologias de analogias, os custos e benefícios da multicelularidade, a origem de estruturas recentes (por exemplo, a cabeça), ou a evolução da reproducão sexual. Na próxima década, podemos esperar uma convergência progressiva entre a genética do desenvolvimento e a genética quantitativa.

Palavras-chave: genes homólogos, multicelularidade, analogia, homologia, reproducão sexual.

\section{REFERENCES}

Baldauf SL, Roger AJ, Wenk-Siefert I and DoolitTLE WF. 2000. A kingdom level phylogeny of eukaryotes based on combined protein data. Science 290: 972-977.

BONNER JT. 2000. First signals : the evolution of multicellular development. Princeton, NJ: Princeton University Press.

BRODSKY AK. 1994. The evolution of insect flight. Oxford: Oxford University Press.

BuFFon GL. 1749-1804. Histoire naturelle générale et particulière. Paris: Imprimerie Royale puis Plassan.

Bull JJ. 1983. The evolution of sex determining mechanisms. Menlo Park, CA: Benjamin/Cummings.

Charlesworth B. 1980. Evolution in age-structured populations. Cambridge: Cambridge University Press. 
Charnov EL. 1993. Life history invariants. Some explorations of symmetry in evolutionary ecology. Oxford: Oxford University Press.

DARWIN C. 1859. On the origin of species by means of natural selection, or the preservation of favoured races in the struggle for life. London: Murray.

DARwin C. 1871. The descent of man and selection in relation to sex. London: J. Murray.

De Rosa R, Grenier JK, Andreeva T, Cook CE, Adoutte A, Akam M, Carrol SB and Balavoine G. 1999. Hox genes in brachiopods and priapulids and protostome evolution. Nature 399: 772-778.

DobZhansky T. 1973. Nothing in biology makes sense, except in the light of evolution. Amer Bio Teacher 35: $125-129$.

GeHRING W. 1998. Master control genes in development and evolution: the homeobox stores. New Haven, Conn: Yale University Press.

Gerhart J and Kirschner M. 1997. Cells, Embryos and Evolution. Malden, Mass: Blackwell.

Gould SJ. 1996. Full house. New York: Harmony Books.

Hamilton WD. 1964. The genetical evolution of social behaviour. J Theoret Biol 6: 1-52.

JablONKA E AND LAMB MJ. 1995. Epigenetic inheritance and evolution. Oxford, UK: Oxford University Press.

JАСОB F. 1977. Evolution and tinkering. Science 196: 1161-1166.

Lamarck JB. 1809. Philosophie zoologique. Paris: Dentu.

Le Douarin NM and Kalcheim C. 1999. The neural crest. Cambridge, UK: Cambridge University Press.

Le Guyader H. 1998. Etienne Geoffroy Saint-Hilaire. Paris: Belin.
Maynard Smith J. 1978. The evolution of sex. Cambridge, UK: Cambridge University Press.

Maynard Smith J and Szathmary E. 1995. The major transitions in evolution. Oxford: Oxford University Press.

MAYr E. 1982. The growth of biological thought. Cambridge, Mass.: Harvard University Press.

Nilsson DE and Pelger S. 1994. A pessimistic estimate of the time required for an eye to evolve. Proc Roy Soc London B 256: 53-58.

Ohlsson R, Hall K and Ritzen M. 1995. Genomic imprinting. Cambridge, UK: Cambridge University Press.

Онмо S. 1970. Evolution by gene duplication. Berlin: Springer.

Piveteau J. 1950. Le débat entre Cuvier et Geoffroy Saint-Hilaire sur l'unité de plan et de composition. Rev d'Hist Sci 3: 343-363.

PopPer K. 1972. Objective knowledge. Cambridge, UK: Cambridge University Press.

Roff DA. 1992. The evolution of life histories. Theory and analysis. London: Chapman \& Hall.

Russo VEA, Martienssen RA and Riggs AD. 1996. Epigenetic mechanisms of gene regulation. Cold Spring Harbor: Cold Spring Harbor Press.

Stearns SC. 1992. The evolution of life histories. Oxford: Oxford University Press.

Steele EJ, Lindley RA and Blanden RV. 1998. Lamarck's signature. Reading, Mass: Perseus Books.

StricKBerger M. 1990. Evolution. Boston, Mass: Jones and Bartlett. 